\title{
O TRABALHO DO PROFESSOR DE LÍNGUA PORTUGUESA: SINGULARIDADES DO GÊNERO DA ATIVIDADE MEDIADA PELA SEQUÊNCIA DIDÁTICA
}

\section{THE WORK OF THE PORTUGUESE LANGUAGE TEACHER: SINGULARITIES OF THE GENRE OF ACTIVITY MEDIATED BY THE DIDACTIC SEQUENCE}

\author{
Cláudia L. N.Saito* \\ Universidade Estadual de Londrina, Londrina, PR, Brasil \\ Daniela da Silva** \\ Universidade Estadual de Londrina, Londrina, PR, Brasil \\ Elvira Lopes $\mathcal{N}$ ascimento*** \\ Universidade Estadual de Londrina, Londrina, PR, Brasil
}

\begin{abstract}
Resumo: Com o objetivo de compreendermos até que ponto determinadas aç̃oes articuladas a cursos de formaccão contínua de professores de LP contribuem para abrir espacos de desenvolvimento no sentido da eficiência que Clot e Faita (2000) denominam como desenvolvimento do poder de agir, buscamos respostas para questões sobre como uma proposta de formação e de ensino de âmbito nacional tem sido interpretada, representada e colocada em prática por uma docente em escola pública. Com foco na implementação de uma sequência didática, a investigação busca dados empíricos na análise das representações dessa professora sobre o trabalho que foi prescrito e planejado por outrem. Algumas considerações apontadas como resultados da pesquisa apontam para um processo emergente da interacão de contradicõoes e conflitos entre os recursos psicológicos já disponiveis na professora e a tensão resultante das atividades impedidas ou contrariadas por diferentes fatores próprios da situação de trabalho.
\end{abstract}

Palavras-chave: Projetos para transposição didática de gêneros. Formação docente. Ensino de língua materna.

Abstract: With the purpose of finding answers to questions mainly about how the proposed training and education has been interpreted, represented and acted upon by teachers in public schools focusing on the implementation of the instructional sequence, the investigation seeks empirical data to analyze representations of a teacher on a task prescribed and planned by somebody else. Some considerations appointed as research results, indicate a process resulting from the interaction of contradictions and conflicts between the psychological resources already available on the teacher and the resultant tension from the precluded activities or countered by particular factors of the working condition.

Keywords: Project for Didactic Transposition of Text Genres; Teacher Training; Mother Tongue Teaching.

* Professora Adjunta da Universidade Estadual de Londrina - UEL, Paraná, Brasil; cln_saito@ yahoo.com.br

** Mestre pela Universidade Estadual de Londrina - UEL, Paraná - Brasil; danisil167@hotmail. com

*** Professora Associada da Universidade Estadual de Londrina - UEL, Paraná - Brasil; elopes@ sercomtel.com.br 
Linha D’Água (Online), São Paulo, v. 28, n. 2, p. 154-171, dez 2015

\section{Introdução}

Entre os objetivos desta investigação, destacamos a busca de compreensão sobre até que ponto determinadas ações articuladas a cursos de formação contínua de professores de LP podem contribuir para abrir espaços de desenvolvimento no sentido da eficiência que Clot e Faita (2000) denominam como desenvolvimento do poder de agir. Com base em Vygotsky (2003) e pensando na formação de professores, partimos do pressuposto de que o desenvolvimento se caracteriza pela reorganização do funcionamento psíquico constituindo "zonas de desenvolvimento potencial” (BRONCKART, 2013). Para esse autor, a questão do desenvolvimento deve ser posta simultaneamente em termos de continuidade e ruptura, ou seja, na passagem do externo para o interno em que emerge a contradição, a tensão, o conflito com aquilo que constitui uma organização psíquica anterior. Entretanto, como enfatiza Bronckart (2013), os aportes externos são geradores de desenvolvimento apenas na medida em que os conflitos que geram sejam "gerenciáveis" pela pessoa em seu estado atual de desenvolvimento.

Nessa perspectiva, o "desenvolvimento do poder de agir" a que se referem Clot e Faita (2000) implica para nós, formadores de professores, a identificação dessa "zona potencial de eficácia", a porta que se abre para que o formador proponha os elementos que lhe parecem exploráveis. Assim, caberá ao formador de profissionais que a sua intervenção formativa procure articular o real e o realizado, o individual e o coletivo, mobilizando metodologias que privilegiem a mediação da linguagem para a compreensão e transformação do gênero profissiona ${ }^{1}$. A intervenção do formador deve ajudar os trabalhadores a fazer emergir a contradição, a tensão, o conflito com o que se propõe a fazer e aquilo que constitui a organização psíquica anterior, fruto da história de vida e das experiências vivenciadas.

Nesse sentido é que o conceito de atividade impedida que Clot (1999) integrou à ideia de conflito nos ajuda a compreender certas tensões vivenciadas no dia a dia de professores, por nos permitir “incorporar o possível ou o impossível na atividade, preservando assim as nossas hipóteses de compreender o desenvolvimento e o seu sofrimento" (CLOT, 2006, P.14). Como afirma o autor, o que produz

Na abordagem de Clot (1999[2006, p. 228]), a noção de gêneros de enunciados bakhtiniana é ampliada para gêneros sociais da atividade, de modo a abarcar, não apenas gêneros de enunciados, mas também "gêneros de técnicas" configurados em gestos que fazem a ponte entre a operacionalidade dos recursos materiais disponíveis e os modos de agir e de pensar de um meio social. O gênero profissional retém a memória das regras implícitas que o tramam e é, ao mesmo tempo o instrumento técnico e psicológico desse meio de vida. Para Nascimento (2004), os gestos profissionais constituem índices de operacionalidade para os que os acionam nas práticas educacionais, permitindo identificar o gênero da atividade do professor e os modos de realização desta atividade. 
tensão e cansaço físico e mental no professor é a atividade impedida, a atividade que retorna, a atividade impossível, a atividade não realizada.

Entre as tensões que se relacionam às atividades educacionais no Brasil está a tarefa de promover letramento para a atuação dos sujeitos em usos da linguagem que se deslocam cada vez mais para os letramentos críticos, o contato entre culturas locais, culturas valorizadas e cultura escolar, a constituição de identidades de sexo e de gênero e de subjetividades nos usos da linguagem na diversidade de contextos de ensino-aprendizagem. Letramentos críticos que trazem ao professor a tarefa de tratar os textos/enunciados como materialidades de discursos, carregados de apreciações valorativas e ressonâncias ideológicas.

A tarefa de promover tais letramentos se articula aos dispositivos didáticos que sejam verdadeiramente adaptados em uma didática da língua materna que possa promover os objetivos de aprendizagem da área de Linguagens na Educação Básica, conforme se postula na versão posta em discussão do documento para a Base Nacional Comum Curricular (BNCC):

[...] assegurar uma formação que possibilite ao estudante interagir com práticas de linguagem, reconhecer as condições de produção das práticas de linguagem, refletir sobre os usos das linguagens e os efeitos de sentido dos recursos expressivos, compreender a diversidade de manifestações linguísticas, artísticas e corporais como construções sociais e culturais, interagir com o outro, reconhecer a dimensão poética e estética como constitutiva das linguagens (BRASIL, 2015, p. 31).

O intuito da BNCC é favorecer a fluência na compreensão na leitura, produção, criação e fruição e o "gradativo domínio de planejamento, revisão e produção, tendo em vista os contextos de circulação dos sujeitos na Educação Básica" (BRASIL, 2015, P. 33). Novamente, os órgãos oficiais federais documentam e, portanto, prescrevem o que, na atualidade, representa os desafios para o ensino-aprendizagem de línguas: os gêneros de texto no mundo contemporâneo.

No âmbito das atividades relacionadas ao Grupo de Pesquisa GEMFOR, no projeto de pesquisa Atividades de linguagem e trabalbo educacional (ALTED), desenvolvido na UEL, as nossas investigações recaem em dois focos de observação: por um lado, nas questões que envolvem o trabalho real do professor e as implicações que uma determinada opção teórico-metodológica pode trazer para o desenvolvimento do seu métier e dos alunos. Por outro lado, questões relacionadas ao trabalho de transposição didática dos objetos de referência para o ensino de LP nos diferentes níveis em que são geradas tensões: entre o sistema de ensino e as demandas sociais; entre as disciplinas escolares e os saberes de referência em relação 
ao "objeto a ensinar" e, sobretudo, as tensões advindas da recontextualização das prescrições das instâncias oficiais. Na situação de trabalho, o professor vai adaptar as regras do coletivo de trabalho e do gênero profissional para construir os seus gestos, conceber as suas regras e elaborar a sua linguagem.

Nessa perspectiva, este trabalho perpassa por dois polos do trabalho docente: a) o da transposição didática, no que diz respeito aos dispositivos didáticos que organizam as atividades didáticas e os objetos de ensino da disciplina de Língua Portuguesa; b) o do agir docente, ao considerar em uma dimensão discursiva o ensino como trabalho.

\section{0 trabalho do professor e os dispositivos didáticos organizadores do tempo escolar: adaptações e ajustamentos aos contextos escolares}

Amigues (2004) vê o trabalho docente como uma atividade instrumentada e direcionada: direcionada à instituição, aos pais e a outros profissionais; instrumentada, por objetos como as prescrições, os coletivos, as regras do ofício e as ferramentas. Com isso, entendemos que é por meio dessa instrumentalização que os professores poderão cumprir a tarefa de organizar e planejar suas aulas.

A partir do pressuposto de que há diferentes estratégias com a finalidade de organizar o trabalho docente e, consequentemente, o tempo escolar, e de que estas, possivelmente, causam dúvidas em como utilizá-las para organizar as aulas, buscamos delinear características de dois dispositivos didáticos capazes de mediar o ensino-aprendizagem na disciplina de Língua Portuguesa: as Sequências Didáticas (SD) propostas por Dolz, Noverraz e Scheneuwly (2004) e as SD propostas pela Olimpíada Nacional de Língua Portuguesa (ONLP) e implementadas por professores da rede pública brasileira.

Entre as formas de organização do trabalho escolar, professores se referem a diferentes dispositivos didáticos: projetos de letramento, projetos didáticos de gêneros, sequências didáticas da Olimpíada Nacional, sequências didáticas da revista Nova Escola e outras formas de planificação do trabalho escolar. Consideramos que todos esses dispositivos apresentam a sequência didática proposta pelo Grupo de Genebra como pilares dessas propostas, ainda que apresentem singularidades ao serem implementadas em situações e contextos particulares, tais como: o trabalho com a leitura (incluindo a leitura do não verbal) de gêneros relacionados com as práticas sociais da comunidade em questão; a avaliação dos textos produzidos pelos alunos construída sob critérios pensados, coletivamente, em sala de aula; o foco em um determinado gênero, mas com a entrada de outros gêneros durante o 
processo sem negligenciar as reflexões sobre as mediações de um gênero a outro; a articulação de ações significativas e contextualizadas à SD que é o foco da atenção.

Como exemplo dessa articulação intergenérica na SD, citamos a SD com o debate oral na sala de aula, gênero catalisador de gestos didáticos (NASCIMENTO, 2015) que envolveram a gestão de multiatividades didáticas implicadas no trabalho com gêneros escritos. $\mathrm{O}$ debate oral possibilitou ações que remeteram a outros gêneros de texto, nesse sentido foi um mega instrumento simbólico (SCHNEUWLY, 2004) que permitiu a seleção de aspectos que foram alvo das investidas do professor e que implicaram a mobilização de diferentes gêneros textuais. Do debate oral sobre um tema controverso, a professora pode dar aos alunos a tarefa de registrarem argumentos a favor ou contra, e ainda solicitar a produção de uma lista escrita; da tese que foi defendida com argumentos validados (ou não) pela turma, a professora solicitou aos alunos a produção de um texto de opinião para o jornal escolar e uma carta de reclamação destinada a uma autoridade.

Assim, se a SD tem como foco de atenção os domínios da leitura, produção escrita, produção oral e análise linguística relacionados a um gênero de texto centralizador para um projeto de comunicação, isso poderá ser articulado com naturalidade a outras ações de linguagem configuradas em diferentes gêneros textuais. Cabe ao professor decidir se em uma determinada turma os alunos já desenvolveram um certo nível de capacidades de linguagem que serão acionadas nessas tarefas.

Nessa perspectiva, consideramos que estamos implementando uma inovação bem adaptada aos recursos para o agir explicitados e sugeridos pelos dispositivos didáticos inspirados na proposta de Dolz, Schneuwly e demais autores filiados ao Grupo de Genebra ao contexto do Brasil. Nossa experiências com sequências didáticas, em todos os níveis da Educação Básica, demonstraram a validade, a viabilidade e a importância dessas adaptações brasileiras ao trabalho pioneiro apresentado pelos autores.

\section{Sequências didáticas: instrumentos para mediar transformações}

No momento em que o MEC conclama a sociedade para discussões sobre o documento que propõe a estados e municípios uma Base Nacional Comum Curricular (BNCC) para a padronização de pelo menos 60\% do currículo da educação básica, tornam-se cruciais as reflexões sobre dois caminhos que serão abertos com essa proposta: o primeiro será a mudança na formação (inicial e continuada) dos professores e o segundo é a reestruturação do material didático. Ambos 
Linha D’Água (Online), São Paulo, v. 28, n. 2, p. 154-171, dez 2015

perpassam pelos objetivos gerais do componente Língua Portuguesa apresentados no documento e explicitados na p.43.

Nos sete objetivos gerais apresentados pela BNC para o componente curricular, pode-se entrever o pressuposto de que os gêneros textuais devem ser o centro do processo de ensino de produção e compreensão das práticas discursivas orais, escritas e multimodais. Assim, volta à cena (se é que algum dia saiu), a prescrição de que o ensino das atividades de produção e leitura deve tomar os gêneros textuais como unidades de ensino, o que continuará a dar propulsão à grande proliferação de pesquisas voltadas para a clarificação do conceito de gênero, para o modo como ensiná-los e para tratar do desenvolvimento de capacidades de linguagem dos alunos por meio desse ensino.

A nosso ver, as prescrições e pesquisas desenvolvidas fortalecem o pressuposto de que "o gênero pode ser considerado como um instrumento psicológico no sentido vygotskiano do termo"(SCHNEUWLY,2004,p. 24), o que fundamenta a tese de que os gêneros de texto devem ser o centro do processo de ensino de produção e compreensão. Tal pressuposto implica uma leitura da noção bakhtiniana de gêneros textuais à luz da psicologia vygotskiana (SCHNEUWLY, 1994) e reflexões sobre a noção de gêneros como "instrumentos psicológicos" que possibilitam a comunicação.

As metáforas de Schneuwly (1994) "gênero é um instrumento" ou "sequência didática é um artefato que pode se constituir em um instrumento do trabalho do professor", têm sido relacionadas ao desenvolvimento do professor e de seu trabalho, levando-nos a retomar a questão: Que efeitos provocam nos sujeitos envolvidos na atividade em que os gêneros são utilizados?

Considerando com Bronckart (2006, p.209), que "a ação é uma intervenção deliberada de um agente humano no mundo" e que "o agente humano precisa de motivo ou razão, intenção e capacidades para realizar gestos", o instrumento é construído pelo sujeito e utilizado para atingir o objetivo da ação, o que provoca transformações psíquicas sobre ele mesmo, regulando o seu próprio comportamento e desenvolvendo capacidades para agir sobre o outro e sobre o mundo. Nesse sentido, a sequência didática passa a ser um instrumento do trabalho do professor, abrindo possibilidades para que ele regule os seus gestos nas atividades modulares que organizam esse dispositivo didático. Assim, o gênero textual que constitui o objeto de estudo passa a ser definido por uma dupla semiotização: porque se trata de um instrumento simbólico de uma prática social e porque, ao ser didatizado, é representado como objeto de aprendizagem, em um processo de apropriação em que o professor seleciona previamente certas dimensões a serem aprendidas (e não outras).

Inserido em uma sequencia didática, esse processo de dupla semiotização do objeto de ensino constitui um sistema de gestos didáticos em que o primeiro 
Linha D’Água (Online), São Paulo, v. 28, n. 2, p. 154-171, dez 2015

passo é a presentificação do objeto de ensino-aprendizagem apresentado como uma prática social, gênero textual pelo qual se dará a interação entre os alunos e os destinatários reais. $\mathrm{O}$ agir praxilógico é viabilizado pelo gênero de texto que instaura uma situação real para a produção textual, a compreensão responsiva ativa e a interação verbal - o que constitui um processo de autêntico letramento.

A seguir, apelando-se à memória e aos conhecimentos prévios do aluno, e visando ao levantamento de dados que permitam obter informação sobre o seu nível de conhecimento naquela prática, solicita-se uma produção inicial que será alvo de uma avaliação diagnóstica para a seleção dos elementos que irão constituir tarefas na sequência de atividades (SD). Essa proposta de produção de texto constitui um gesto didático com a finalidade de propiciar ao aluno a experimentação de diferentes hipóteses e assim construir a sua aprendizagens.

Ao postularmos que o letramento é um processo de apropriação de gêneros textuais assumimos o ponto de vista de que as operações de linguagem envolvidas nas práticas sociais de referência ( DOLZ et al, 2009) implicam saberes e capacidades de linguagem que necessitam de atividades formativas deliberadas. $\mathrm{O}$ trabalho realizado com $\mathrm{SD}$ em inúmeras experiências que temos vivenciado na Educação Básica nos leva a representações do que é o trabalho organizado por esse dispositivo didático que sintetizamos na figura a seguir:

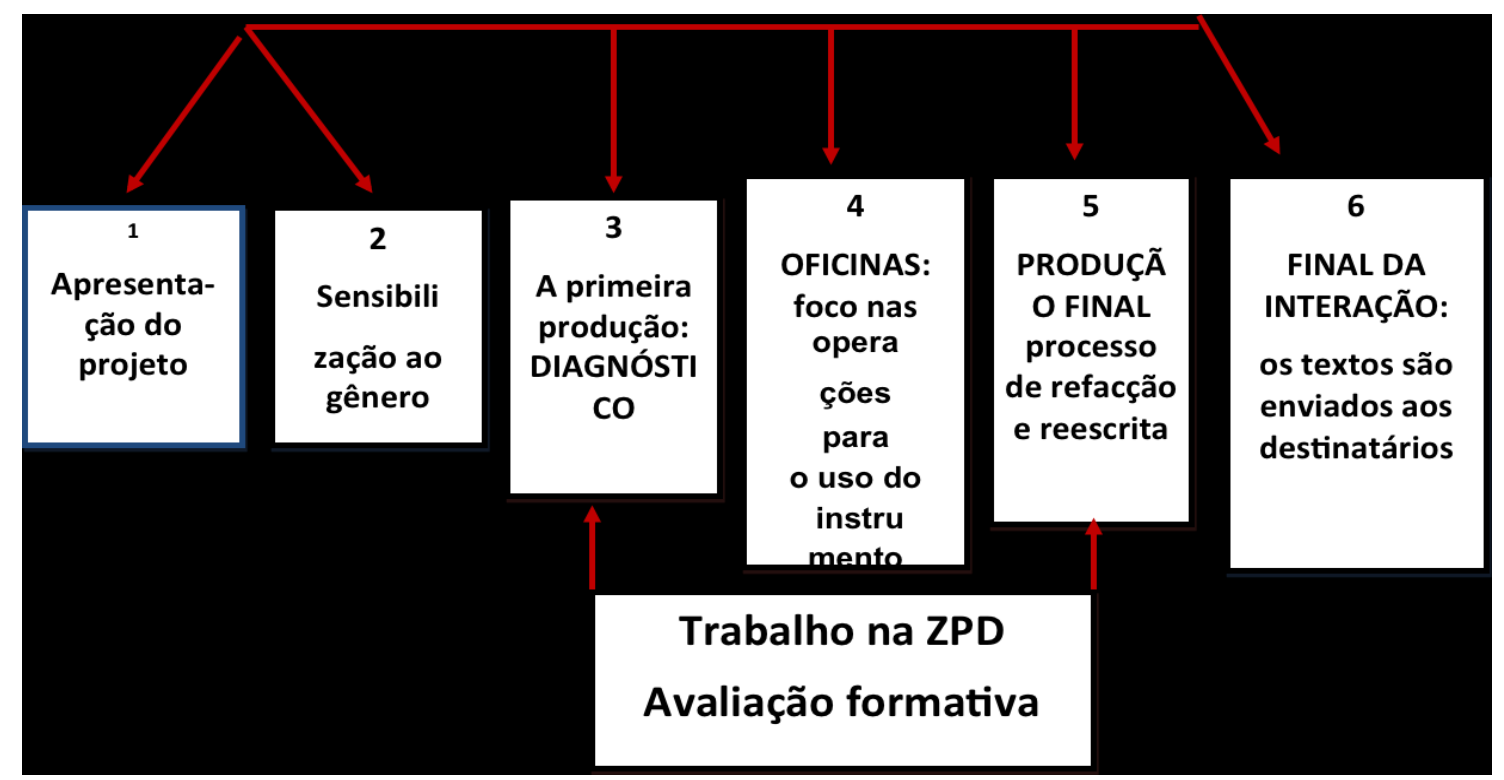

Figura 1: A engenharia didática do Grupo de Genebra

Fonte: Nascimento, 2006 (com base em DOLZ, NOVERRAZ e SCHNEUWLY, 2004) 
Sobre a proposta dos autores do chamado Grupo de Genebra chamamos a atenção para o terceiro módulo do processo sequencial no esquema apresentado na fig.1: a primeira produção, ou seja, a produção inicial que vemos como o motor principal do processo. Considerada primordial por Dolz (2009), essa primeira produção de texto do aluno permite ao professor conhecer o nível de desenvolvimento real do aluno em relação ao objeto de estudo. Permite que o professor diagnostique as dimensões ensináveis do objeto que deve constituir um foco de atenção para o professor e aluno, instaurando um processo de avaliação formativa que só vai ser encerrado na produção final.

A sequência de módulos compreendidos pela sequencia didática na forma como é proposta pelos autores compreende a emergência e a predominância de gestos didáticos fundadores (AEBY-DAGHÉ \& DOLZ, 2008; SCHNEUWLY, 2009; NASCIMENTO, 2014), como explicitamos a seguir:

» Os módulos 1 e 2 (apresentação do projeto de comunicação à classe e sensibilização ao gênero) permitem a retomada e o desdobramento do gesto presentificação (que consiste em mostrar aos aprendizes o objeto de ensino em diferentes mídias e suportes);

" O módulo 3 (a produção inicial oral ou escrita para diagnóstico dos saberes e dificuldades do aluno) permite o desdobramento do gesto delimitaçãolelementarização (que consiste no dimensionamento particular do objeto, o que implica uma desconstrução e uma colocação em evidência de certas dimensões que serão ensinadas a um, a vários ou a todos os alunos);

»Assinalados como Módulo 4, constituem o conjunto de diversas Oficinas em que se trabalham as operações para o uso do gênero de forma a abranger os objetivos de aprendizagem da área de Linguagens (BRASIL, 2015), permitirão o desdobramento dos gestos já referidos e do gesto de formulação de tarefas (para a entrada do objeto no dispositivo didático, gesto pelo qual o professor apresenta consignas/comandos de trabalho), colocando em cena diferentes dispositivos didáticos no quadro da atividade escolar. Faz-se pela disponibilização de suportes (textos de apoio, exercícios, corpus de frases para análise, objetos diversos etc).

" O módulo 5 permitirá o desdobramento do gesto de apelo à memória (para resgatar objetos já trabalhados e permitir a articulação com o novo objeto de saber).

» O módulo 6 (os textos são enviados aos destinatários, completando assim a função social da escrita), desdobrando o gesto de tessitura de todas as fases percorridas até chegar ao destinatário real da produção. 
O módulo 6 deixa explicitado uma importante característica da sequência didática na metodologia proposta pelos autores de Genebra: propicia o desdobramento dos gestos profissionais fundadores do professor de língua materna para mediar a aprendizagem segundo os objetivos de aprendizagem organizados nos cinco eixos postulados pelo BNCC (2015): leitura, oralidade, formação literária, escrita, análise linguística, sempre na perspectiva uso-reflexão-uso.

O processo instaurado pelos diferentes módulos da sequencia didática proposta por Dolz, Noverraz e Schneuwly (2013, p.82) abrem um leque de opções para os gestos de regulação das aprendizagens e do desenvolvimento dos aprendizes uma vez que o professor, à medida que vai caminhando pelas atividades dos módulos, observa e avalia as capacidades, competências, interesses e aptidões, o que faz dessa avaliação formativa uma parte integral e natural da aprendizagem, justamente porque desencadeiam os gestos de Regulação do professor e de Autorregulação pelo aluno, o que vai de encontro aos postulados da Base Nacional Comum Curricular (BRASIL, 2015) que enfatiza o reconhecimento de estratégias de planejamento, rescrita, revisão e avaliação dos textos.

Concordamos com Dolz $(2015)^{2}$ quando afirma que alguns dispositivos de ensino são "parciais" em relação à proposta original dos autores de Genebra. Ao se referir aos desafios do letramento no Brasil, o autor genebrino insiste sobre certas "fraquezas" da SD em algumas adaptações feitas no Brasil, sobretudo as relacionadas à ausência de avaliação das produções iniciais, indispensáveis para que o professor responda a questões como: Com quais capacidades o aluno está iniciando esse processo de aprendizagem (em determinado projeto, ano ou série)? Até que ponto o aluno aprendeu ou cumpriu metas estabelecidas (em ano, série ou projeto anterior), em termos de capacidades esperadas, nessa etapa da escolaridade? $\mathrm{O}$ aluno se encontra em atraso ou adiantado em relação aos demais alunos? Quais serão os procedimentos adotados para o monitoramento do processo de desenvolvimento desse aluno?

\section{A transformação de um instrumento técnico em instrumento psicológi- co para a gestão da ação do sujeito}

Para o agir educacional o professor aciona recursos materiais e simbólicos (linguageiros) que são instrumentos de trabalho em diferentes suportes, com os quais vai mediar o processo de ensinar e de aprender. Nessa perspectiva, os

2 Em comunicação oral durante o VIII SIGET - Simpósio Internacional de Estudos de Gêneros Textuais, USP-SP, 2015. 
instrumentos de mediação utilizados por uma professora constituem uma fonte de observação cujos dados nos ajudam a compreender como se dá o agir educacional no processo de implantação de uma sequência didática da Olimpíada de Língua Portuguesa (ONLP): Escrevendo o Futuro". Por iniciativa do MEC, juntamente com a Fundação Itaú Social (FIS), que tem como coordenação técnica o Centro de Estudos e Pesquisas em Educação, Cultura e Ação Comunitária (CENPEC), essas entidades visam a um único objetivo: proporcionar ensino de qualidade para todos. De acordo com os organizadores da competição, a Olimpíada é um meio oficial de contribuir para a formação de professores da rede pública.

Dessa maneira, a ONLP tem o papel de agir como instrumento de mediação nas atividades que visam à formação de professores, atua no desenvolvimento de competências, implementando intervenções formativas na educação básica.Temos, assim, um processo de dupla formação: um mesmo material contribui para o desenvolvimento de capacidades linguísticas dos alunos, ao mesmo tempo em que orienta e promove a formação docente. Portanto, vemos a sequência didática da ONLP como um texto prescritivo, uma vez que apresenta ao professor o trabalho "que deve ser realizado", anterior ao trabalho propriamente dito, diz o que deve ser feito para a realização das tarefas nas oficinas, ainda que esclareça que o professor poderá adaptar e ajustar esse instrumento.

Ao mobilizarmos o conceito de atividade desdobrado em atividade realizada e real da atividade (CLOT; FAITA,2000) ${ }^{3}$, pretendemos analisar e descrever para compreendermos como o gênero da atividade profissional é desencadeado por essa SD. Nesse coletivo profissional, um determinado professor se coloca em isolamento (para se sair bem na competição), o que o coloca em confrontação com as tensões e contradições de uma forma de organização do trabalho que pode, até certo ponto, deixá-lo sem voz face ao real prescrito para a atividade.

A investigação busca dados empíricos no trabalho prescrito pela ONLP, o trabalho realizado, visível nas interações com os alunos e o trabalho real, que implica também o trabalho realizado e as atividades contrariadas ou impedidas por diferentes fatores. Ao (re)construir o gênero profissional em conformidade com o que se postula na formação da ONLP, a professora - sujeito da nossa pesquisa - se

3 Clot (1999 [2006]) retoma a divisão da Ergonomia entre o trabalho prescrito (ou seja, as prescrições que as instituições/empresas prescrevem para prefigurar o trabalho e a realização de tarefas específicas) e o trabalho visivelmente realizado. O autor reformula essas duas dimensões introduzindo uma terceira, o trabalho real, onde inclui as atividades contrariadas do trabalhador, as que ele poderia desenvolver, mas são impedidas por diferentes fatores da situação de trabalho. 
Linha D’Água (Online), São Paulo, v. 28, n. 2, p. 154-171, dez 2015

depara com tensões e conflitos que tem de gerenciar, mas que se revelam também como recursos para a sua própria ação.

\subsection{O real da atividade mediada pelo dispositivo didático da ONLP}

A pesquisa foi realizada em uma escola pública, situada em um pequeno município do Norte do Paraná. O trabalho foi desenvolvido em uma turma do nono ano, que contava com 35 alunos, oriundos da zona rural e urbana. A professora é formada em Letras e atua há 20 anos na rede pública. O ponto de atenção do material didático da ONLP é o gênero crônica e compreende onze oficinas que levam, em média, três ou quatro aulas, o material se completa com um "Cronograma de Atividades", cartaz que é afixado na sala dos professores e consultado regularmente. A pesquisa global foi realizada por meio da análise, na perspectiva do interacionismo sociodiscursivo de textos prescritivos oficiais que norteiam o trabalho da docente e da própria ONLP, o Caderno do Professor na ONLP, assim como os registros em áudio e vídeo das aulas, entrevistas antes, durante e após o trabalho, a sinopse da sequência didática da ONLP, a sequência didática integral da ONLP, os dispositivos didáticos introduzidos pela professora, diferentes daqueles oferecidos pela OLP e os textos dos alunos produzidos no final da SD.

Com o objetivo específico de identificar indícios das tensões emergentes no trabalho com a SD para tentarmos compreender se essas contradições e conflitos constituíram potencialidades para o desenvolvimento profissional, buscamos respostas às seguintes questões: Durante a implementação da SD da ONLP, quais são os gestos de adaptação ao contexto de ensino que promovem mudanças no trabalho prescrito pela OLP? Essa adaptação promove índices de tomada de consciência e gera desenvolvimento na professora durante a implementação da SD da ONLP?

As entrevistas da professora no decorrer da SD deixaram entrever dificuldades relacionadas aos saberes sobre o gênero (crônica) que "deveriam" ser ensinados sem a produção inicial que apontaria aspectos a serem trabalhados no desenvolvimento das oficinas. $\mathrm{Na}$ ausência de uma produção inicial, não houve o levantamento de um conjunto de fatores que poderiam ser associados às dificuldades de aprendizagem da produção escrita de texto. As oficinas da SD a ser implementada pela professora foi planejada e elabora por outrem, o que deu a algumas oficinas uma aparente falta de coerência teórica e metodológica com as finalidades e os objetivos pedagógicos.

De acordo com o ideário vygotskiano, as rupturas resultantes da interação conflitual entre os recursos psicológicos de um indivíduo e os recursos novos que lhe são propostos pelo meio cultural, propiciam desenvolvimento apenas na medida 
em que os conflitos que eles geram sejam "gerenciáveis" pela pessoa em seu estado atual de desenvolvimento. Nesse sentido, buscamos conhecer o trabalho prescrito pela ONLP em articulação ao real e realizado, o individual de uma professora e o coletivo, privilegiando a mediação da linguagem na reconstrução do gênero profissional instaurado pelo trabalho na ONLP. No trabalho real, buscamos indícios das tensões identificadas que potencializaram desenvolvimento e se refletiram em ações transformadoras do agir profissional.

\subsection{Tensões e conflitos gerando desenvolvimento na transposição didática}

\begin{tabular}{ll}
\hline \multicolumn{1}{c}{ OFICINA 3 - O TRABALHO PRESCRITO PELA OLP } & \multicolumn{1}{c}{ OFICINA 3 - O TRABALHO REALIZADO } \\
\hline Prescrição de 4 etapas: & $21 / 05 / 2012:$ \\
Etapa 1 & Etapa 1 \\
Socialização da pesquisa sugerida na oficina & - Socialização da pesquisa: passear pela cidade e \\
anterior - trazer crônicas. & trazer um tema para ser escrito. \\
$\begin{array}{l}\text { Discussão sobre as características das crônicas, com } \\
\text { base nas crônicas trazidas pelos alunos. }\end{array}$ & - TV pendrive: vídeo com o hino e alguns \\
& espaços importantes da cidade. O vídeo travou.
\end{tabular}

$\begin{array}{ll}\begin{array}{l}\text { Etapa 2 } \\ \text { - Escolha de um assunto/tema e do tom a ser } \\ \text { utilizado na escrita, com auxílio do professor. }\end{array} & \begin{array}{l}\text { Etapa 2 } \\ \text { - Orientação sobre a produção da crônica: } \\ \text { conversa ao pé do ouvido; o tipo de linguagem e } \\ \text { pensarem sobre o tema (atual). }\end{array} \\ \begin{array}{l}\text { Etapas 3 e 4 } \\ \text { - Exemplo de análise de produção de crônica }\end{array} & \begin{array}{l}\text { Etapa 3 } \\ \text { - Produção de crônicas na sala de aula. }\end{array} \\ \text { produzidas. } \\ \text { - Pesquisa de crônicas que trazem como tema: } \\ \text { "bola e amor”. }\end{array}$

Quadro 1: Quadro comparativo entre o trabalho prescrito pela OLP e o trabalho realizado pela professora na oficina 3.

As tensões e conflitos gerados no processo de transposição prescrito pela ONLP significam a oportunidade para a reorganização de significações provenientes das contradições entre a proposta metodológica a partir de um gênero textual como referência para uma série de atividades e os modos de fazer cristalizados por anos de práticas dessa professora. Amparada pelo Caderno do Professor, os materiais e a prática devem ser adaptados ao contexto escolar. O espaço deste texto nos permite apresentar $\mathrm{m}$ recorte do trabalho prescrito pela ONLP pelo qual buscamos dados comparativos relacionados ao trabalho realizado.

O quadro 1 apresenta duas colunas: na coluna da esquerda, apresenta-se o passo a passo da organização do trabalho na forma como é prescrita pela ONLP; 
na coluna da direita, a organização passo a passo da forma como a professora organiza e desenvolve esse trabalho na situação de sala de aula. As duas colunas na tabela traçam um panorama comparativo entre o trabalho prescrito pela OLP e o trabalho real implementado pela professora na oficina 3 da SD.

Em relação à Oficina 3, verificamos profundas diferenças no modo de conduzir a Etapa 1, pois a professora adapta e ajusta a proposta do material ao perceber que os alunos estavam "desligados" da atividade. Ela recorre ao gesto de pedir para os alunos "pesquisarem o tema passeando na própria cidade e observando alguns lugares". Essa tarefa estava contradizendo a que foi prescrita pela oficina da OL: o professor devia direcionar os alunos a pesquisarem crônicas. Além disso, essa oficina prescrevia a análise de algumas características da crônica, a partir dos textos trazidos pelos alunos, e não a sua produção. A professora, ao contrário, adapta essa tarefa a outra que ela sugere e que considera mais adequada para os seus objetivos de trabalho. Dessa forma, ela reorganiza, pula essas etapas do texto prescritivo da ONLP para já solicitar a produção. Ao agir dessa maneira ela ignora a orientação da SD e reorganiza o seu trabalho. Assim, como defende Clot (2001) identificamos que o operador, ou seja, a professora reorganiza, reconceptualiza, redefine o trabalho a sua maneira, deixando evidente o afastamento do trabalho prescrito.

O salto das etapas do trabalho gera tensões entre o que ela decide implementar e o a prescrição, entre o seu processo de ensino e o de aprendizagem dos alunos. Torna-se tensa a interação entre professora e alunos, sobretudo com relação às expectativas das capacidades dos alunos de apresentarem "ao menos um rascunho de crônica”. Ela descreve oralmente características do gênero, mas pouco consegue realizar. A ausência de instrumentos materiais e semióticos para mediar esses momentos de tensão se torna um obstáculo: ela não conta com recursos para mediar as operações mentais dos alunos relacionadas às características do gênero que os ajudem na produção.

As tarefas da Oficina 3 produzem tensão na professora: as dificuldades dos alunos são "quase intransponíveis" e, para ela é perturbador o modo de organização do trabalho, novo para ela e para os alunos. O foco de atenção nessa etapa do trabalho é o tema da crônica que deverão produzir para a competição. A professora alega "falta de tempo" para poder resgatar, nos outros materiais didáticos fornecidos pela ONLP sugestões do que poderia ser dizível nos textos. Ela não consultou as várias edições da revista $\mathrm{Na}$ Ponta do Lápis e no Caderno do Professor, disponibilizados para os professores ${ }^{4}$ Lá, ela teria encontrado diversas sugestões de temas que responderiam à

4 A revista $\mathrm{Na}$ Ponta do Lápis é destinada a professores que trabalham com leitura e escrita em língua portuguesa nas escolas públicas. Criada em 2005 e de periodicidade quadrimestral, é a publicação oficial da Olimpíada de Língua Portuguesa Escrevendo o Futuro, divulgando a metodologia do pro- 
questão: $\mathrm{O}$ que poderia ser tema de uma crônica? "Todos os seus sonhos, todos os seus segredos e todas as suas ideias" (Na Ponta do Lápis, p. 17); "O lugar onde vivo" (idem); "O mundo mostrado de um jeito novo com a intenção de sensibilizar, convencer, fazer pensar ou divertir os leitores/ouvintes" (Caderno do Professor, p. 18); "Mostrar um olhar próprio, inovador, uma visão diferente das coisas que despertam emoções" ( Na Ponta do Lápis, 11, p. 40); "As plantas, a natureza, o sabor das frutas, as peculiaridades da paisagem" (Na Ponta do Lápis, 11, p. 46).

A inquietação da docente diante das dificuldades dos alunos é bem visível. A todo momento ela senta e, logo em seguida, levanta. Faz anotações na lousa. De momento em momento, "despeja" oralmente informações sobre as características do gênero para os alunos. Os dados comparativos gerados pelas demais oficinas repetem esse fato: a professora tem sobre a mesa o Caderno do Professor com a SD que deve seguir, mas salta atividades ou as adapta, conduzida pelos fatores que implicam coerções sobre o seu trabalho.

Como os alunos não trouxeram uma produção de crônica de casa, tornam-se evidentes os indícios da tensão gerada no trabalho efetivamente realizado: a professora necessita daquelas produções para identificar e diagnosticar as dificuldades dos alunos com relação ao gênero, ela "sabe" que sem aquela produção feita em casa não há como progredir com as oficinas. A situação real apresenta impedimentos para o agir e isso interfere no seu estado emocional, gera estresse, desapontamento, ansiedade. $\mathrm{O}$ resultado da tarefa não realizada, impedida se revela no cansaço e desânimo da professora no trabalho que "deve" executar para a realização da ONLP.

Improvisa atividades afastando-se do texto prescritivo, recorrendo em vários momentos a atividades de classificação das unidades de linguagem - resquício do ensino tradicional pautado em classificações metalinguísticas. Foca a atenção nas "figuras de linguagem" em fragmentos de frases, gerando aqui mais uma fonte de tensão em relação ao objeto a ser ensinado e a oscilação entre o procedimento tradicional de classificar "classes" que pouco ou nada tem a ver com o trabalho com gêneros textuais. A professora expressa a tensão que essa dificuldade lhe traz, ao afirmar que "sabe" disso, pois os textos prescritivos oficiais, os conceitos trabalhados nas formações contínuas e na própria formação da ONLP se fundamentam na concepção de linguagem como atividade, como interação entre sujeitos situados sócio-historicamente.

Sobre o fato de ter escrito na lousa as questões sugeridas pela SD, ela explica que se as tivesse trazido impressas, isso agilizaria a sua aula, mas a culpa disso foi "a falta de recursos do colégio”. Essa realidade confirma os postulados de Clot (2001,

grama e disponibilizando conteúdos que contribuem com as ações de ensino da língua. Disponível em https://www.escrevendoofuturo.org.br/conteudo/biblioteca/na-ponta-do-lapis 
p.5), ao defender sobre o fato da necessidade de haver a disponibilização de recursos para o agir do professor, pois quando há a falta desses existe "a privação do exercício de suas responsabilidades", ou seja, impede o trabalhador de trabalhar, o que pode acarretar uma "perturbação" em relação aos valores e ao sentido do trabalho.

Os dados da implementação da SD ampliaram uma característica muito marcante no agir da professora: o agir improvisado. Por reconhecermos que o agir precisa ser motivado, mas que existe uma série de fatores que impedem ou interferem nessa motivação, sintetizamos os motivos que julgamos serem causadores do não cumprimento do trabalho prescrito, as tensões geradas pelos obstáculos à realização das tarefas que potencializaram ações que consideramos geradoras de desenvolvimento profissional:

\begin{tabular}{|c|c|c|}
\hline $\begin{array}{c}\text { MOTIVO DO NÃO } \\
\text { CUMPRIMENTO DA } \\
\text { PRESCRICỸ̃O }\end{array}$ & $\begin{array}{l}\text { TENSÕES QUE POTENCIALIZARAM } \\
\text { DESENVOLVIMENTO }\end{array}$ & ALGUMAS AÇÕES RESULTANTES \\
\hline $\begin{array}{l}\text { - Os alunos não têm } \\
\text { conhecimento sobre o tema } \\
\text { do texto a ser produzido: "O } \\
\text { lugar onde moro" } \\
\text { - Falta de instrumentos } \\
\text { materiais fornecidos pelo } \\
\text { colégio. } \\
\text { - Tempo gasto para passar } \\
\text { as questões da oficina na } \\
\text { lousa } \\
\text { - A não realização das } \\
\text { atividades pelos alunos } \\
\text { - O tempo escolar: pausas } \\
\text { para a realização das provas } \\
\text { bimestrais. } \\
\text { - Necessidade de } \\
\text { antecipação da produção } \\
\text { das crônicas para a } \\
\text { competição. } \\
\text { - Tempo para preparar } \\
\text { outras atividades que } \\
\text { não estavam prescritas e } \\
\text { antecipação da produção. }\end{array}$ & $\begin{array}{l}\text { - O gênero textual versus } \\
\text { enfoque temático; } \\
\text { - O foco no conteúdo temático } \\
\text { prescrito pela ONLP versus a } \\
\text { prática discursiva do cronista; } \\
\text { - O foco na gramática da língua } \\
\text { versus foco na análise linguística } \\
\text { - A burocracia do sistema escolar } \\
\text { versus metodologia por SD; } \\
\text { - O método da SD da ONLP } \\
\text { versus metodologia tradicional } \\
\text { focada no livro didático } \\
\text { - O interesse pelo método } \\
\text { inovador da SD versus o } \\
\text { estranhamento dos alunos e pais } \\
\text { quanto ao objeto de ensino. } \\
\text { - Capacidades docentes versus } \\
\text { planejamento de atividades } \\
\text { complementares } \\
\text { - Compreensão responsiva ativa } \\
\text { versus leitura de decodificação. } \\
\text { - Autonomia versus restrição à } \\
\text { prescrição. }\end{array}$ & $\begin{array}{l}\text {-Organização de pesquisas sobre o } \\
\text { tema "O lugar onde moro". } \\
\text { - Visita à biblioteca da cidade. } \\
\text {-Entrevista a moradores da cidade. } \\
\text { - Apresentação de vídeo clipe com } \\
\text { alguns pontos da cidade. } \\
\text { - Audição do hino da cidade. } \\
\text { - Atividades sobre o hino da cidade. } \\
\text { - Debates orais sobre os temas das } \\
\text { crônicas. } \\
\text {-Leituras jogralizadas. } \\
\text { - Produção de roteiro de peça teatral } \\
\text { baseadas nas crônicas. } \\
\text { - Encenação dos roteiros de peças } \\
\text { teatrais inspiradas nas crônicas. } \\
\text { - Mural de crônicas produzidas pelos } \\
\text { alunos } \\
\text {-A crônica produzida pela professora. } \\
\text {-Expansão das instruções nos } \\
\text { comandos das tarefas da SD da } \\
\text { ONLP. }\end{array}$ \\
\hline
\end{tabular}

Quadro 2: Fatores que influenciaram o agir da professora no desenvolvimento das oficinas na OLP

São vários os fatores que influenciam o trabalho prescrito e promovem modificações no agir real da docente. Sobre as tensões que aparecem no trabalho realizado geradas pelas contradições do modo de organização em que ele se baseia (ou 
deveria) observamos como elas se reproduzem na práxis da professora. Algumas das tensões apontadas emergem da organização do trabalho prescrita pela SD da ONLP que ainda não foi dominado pela professora. Isso colocou a professora em situação periférica em relação ao trabalho prescrito e trouxe resultados no trabalho real. Por outro lado, tensões ocasionadas pelas contradições entre a metodologia tradicional adotada durante anos e a metodologia inovadora proposta pela ONLP a levaram a implementar atividades improvisadas durante as aulas, algumas pulando etapas da $\mathrm{SD}$ e fugindo dos reais objetivos do trabalho com o gênero em foco.

Entretanto, as dificuldades/impedimentos em seu trabalho provocaram, sim, tomadas de consciência sobre os problemas a resolver para os quais ela buscou soluções. Essas tomadas de consciência constituem zonas potenciais de desenvolvimento profissional, pois elas resultaram em rupturas (com concepções anteriores relacionadas à concepção de linguagem e de ensino) e transformações (com a emergência de gestos profissionais inovadores).

\section{Considerações finais}

O trabalho real com a SD fez gerar tensões diante dos obstáculos para a sua realização, evidenciando avanços ou inovações às propostas, mas também a acomodação e a fuga para "modos mais fáceis e rápidos de fazer". Entretanto, no trabalho realizado, encontramos gestos criativos de adaptação e ajustamento ao contexto quando a professora busca reconceptualizar e redefinir prescrições ao introduzir tarefas recorrendo a textos e exercícios diferentes. Nesses momentos, ela se coloca como "ator" capaz de nortear as ações de acordo com seus saberes, sua formação, suas crenças, sua história de vida e profissional. A ONLP permitiu e incentivou a (re)construção das regras do métier valorizadas pela cultura profissional da atualidade que apela pela inovação, o que transformou o gênero profissional da professores no coletivo do trabalho educacional.

A metodologia adotada, ainda que siga parcialmente as propostas do grupo de Genebra (sobretudo em relação à ausência do diagnóstico das capacidades de linguagem dos alunos em uma produção inicial) propiciou desenvolvimento no agir profissional da docente pelo fato de que, ora seguia à risca o material fornecido utilizando a SD como instrumento mediador o que potencializou processos analíticos, abstrações e generalizações sobre a transposição didática da crônica como prática social de referência para o trabalho; ora o adaptava ao contexto real. Esses fatores geraram contradições e tensões na docente o que, como consequência, provocaram transformações de práticas cristalizadas, sobretudo as que se concentram no tratamento do objeto de ensino subjacentes a uma 


\section{Linha D'Água (Online), São Paulo, v. 28, n. 2, p. 154-171, dez 2015}

concepção representacional da linguagem, distantes de uma abordagem comunicativa contextualizada.

Os resultados da investigação demonstram um processo resultante da interação de conflitos entre os recursos psicológicos já disponíveis na professora e a tensão resultante das atividades impedidas ou contrariadas por diferentes fatores próprios da situação de trabalho e das coerções da competição instaurada pela ONLP.

As atividades da SD não realizadas por impedimentos vários demonstram ausências importantes no curso de formação contínua que têm sido repensadas em nosso grupo de pesquisa, tais como as práticas de organização das tarefas em sequências didáticas; questões de resistência relacionadas à voz do coletivo do cotidiano de trabalho; a ausência de discussões de propostas de atividades fundamentadas em um quadro teórico-metodológico com foco no agir educacional e nos gestos profissionais (fundadores e de ajustamento) emergentes nos contextos escolares. Sobretudo, temos repensado a importância do diálogo entre formador e professor-formador durante e depois da implementação da sequência didática na escola.

\section{Referências}

AEBY-DAGHÉ, S.; DOLZ, J. (2008). "Des gestes didactiques fondateurs aux gestes spécifiques à l'enseignement-apprentissage du texte d'opinion", in : BUCHETON, Dominique; DEZUTTER, Olivier (Org.). Le développement des gestes professionnels dans l'enseignement du français: un défi pour la recherche et la formation. Bruxelas: De Boeck, p.83-105.

BRASIL (2015). Base Nacional Comum Curricular. Ministério da Educação, Secretaria de Educação Básica. Documento para Consulta pública.

BRONCKART, J-P. Um retorno necessário à questão do desenvolvimento. In: Gêneros textuais e formação inicial: uma homenagem a Malu Matêncio. BUENO Luzia; TEIXEIRA, Maria Aparecida; Vera Lúcia Lopes CRISTOVÃO. Campinas: Mercado de Letras, 2012, p. 85-109.

Atividade de linguagem, discurso e desenvolvimento bumano. Org. Anna Rachel Machado e Maria de Lourdes M. Matencio. Trad. Anna Rachel Machado e Maria de Lourdes M. Matencio (et al). Campinas, SP: Mercado das Letras, 2006.

CLOT, Y. (2006). A função psicológica do trabalho. Petrópolis (Rio de Janeiro): Editora Vozes.

CLOT, Y.; FAÏTA, D. Genre et style en analyse du travail.Concepts et méthodes. Travailler, no. 4, p. 7-42, 2000. 


\section{Linha D'Água (Online), São Paulo, v. 28, n. 2, p. 154-171, dez 2015}

DOLZ, JOAQUIM; NOVERRAZ, Michele; SCHNEUWLY, Bernard. Sequências didáticas para o oral e a escrita: apresentação de um procedimento. In: DOLZ, Joaquim; SCHNEUWLY, Bernard. Gêneros orais e escritos na escola. Trad. e org. Roxane Rojo e Glais Cordeiro. Campinas: Mercado de Letras, 2004.

GUIMARÃES, Ana Maria Mattos. Gêneros textuais e ensino de língua materna: entre o caminho e a pedra. Revista Brasileira de Linguistica Aplicada, v.10, n.2, 421-438, 2010.

NASCIMENTO, Elvira Lopes. A formação contínua como objeto de investigação: o agir (re) configurado nos gestos profissionais. In: NASCIMENTO, Elvira Lopes; ROJO Roxane (Org.). Gêneros de texto/discurso e os desafios da contemporaneidade. Campinas: Pontes Editores, 2014.

Debate na sala de aula: gênero catalisador para aprendizagens e desenvolvimento. In: Luiza Bueno; Terezinha da Conceição Costa-Hübes.(Orgs.). Gêneros orais no ensino. São Paulo: Mercado de Letras, 2015, pp. 206-237.

ROJO, R. H. R. O texto no ensino-aprendizagem de línguas hoje: desafios da contemporaneidade. In: Luiz Carlos Travaglia; Luisa Helena Borges Finotti; Elisete Maria Carvalho de mesquita (Orgs.). Gêneros de texto: caracterização e ensino. Uberlândia, EDUFU, 2008. p. 9-45.

SAITO, Cláudia Lopes Nascimento; NASCIMENTO, Elvira Lopes. Os gêneros como instrumentos para o ensino e aprendizagem da leitura e da escrita. In: MENEGASSI, R. ; SANTOS, AR ; RITTER, L.C.(org.s). Escrita e ensino. . Maringá : EDIT. da UEM, 2010.

SILVA, Daniela da. Olimpiada de Lingua Portuguesa como instrumento de formação docente. 2014. 181 f. Dissertação (Mestrado em Estudos da Linguagem) - Universidade Estadual de Londrina, Londrina, 2014.

SCHNEUWLY, Bernard. Genres et types de discours: considérations psychologiques et ontogénétiques. In: REUTER, Y. (Org.). Les interactions lecture écriture. Berna: Peter Lang, 1994. P. 155-173.

VOLOCHINOV, V. N./BAKHTIN, M. M. Marxismo e Filosofia da Linguagem. São Paulo: Hucitec, 1995[1929]. Trad. Michel Lahud. Yara Frateschi Vieira. 7 ed.

VYGOTSKY, L. S. (1998). Pensamento e Linguagem. Tradução Jefferson L. Camargo. 2a ed. 4a tiragem. São Paulo: Martins Fontes. 